\title{
СПОСОБЫ ВКЛЮЧЕНИЯ ЛЕКСИЧЕСКИХ ЕДИНИЦ В УЧЕБНОЕ ОБЩЕНИЕ
}

\section{WAYS TO INCLUDE LEXICAL UNITS IN EDUCATIONAL COMMUNICATION}

\section{Chen Xue}

Summary: The work is devoted to the formation of lexical skills. Modeling of educational activities on the formation of foreign (Chinese) students lexical skills and abilities will allow them to communicate on the optimal parameters. The aim of the work is the selection of lexical material for professionally oriented teaching of the Russian language and the definition of the methodology for the formation of lexical skills in Chinese students at the initial stage.

Keywords: lexical unit, experience and skills, chinese students, elementary level.

\author{
Чэнь Сюе \\ соискатель, преподаватель, Астраханский \\ государственный университет \\ 437118032@q9.com
}

Аннотация: Работа посвящена формированию лексических навыков и умений. Моделирование учебной деятельности по формированию у иностранных (китайских) учащихся лексических навыков и умений позволит им осуществлять коммуникацию по оптимальным параметрам. Целью работы является отбор лексического материала для профессионально ориентированного обучения русском языку и определение методики формирования лексических навыков и умений у китайских учащихся на начальном этапе.

Ключевые слова: лексическая единица, навыки и умения, китайские учащиеся, начальный этап.
K ак мы думаем, педагогическая стратегия, направленная на изначальное включение ЛЕ в коммуникацию, несколько отличается от традиционной педагогической стратегии. Так, в соответствии с традиционной педагогической стратегией преподаватель сначала формирует у учащихся лексические навыки (которые формируются за счёт тренировочных, языковых. Упражнений), а затем уже умения, включающие сформированный навык в структуру общения. Мы считаем, что в отношении языковой личности (ЯЛ) китайского учащегося начального этапа (НЭ) обучения такая стратегия не подходит. Поскольку ЯЛ китайского учащегося правополушарна (Бобрышева, 2004, Мухаммад, Ван Лися, 2017), и, следовательно, при обучении/коммуникации тяготеет к когнитивной стратегии «от синтеза - к анализу», мы думаем, что работа в данной аудитории изначально должна строиться на таких коммуникативных единицах, как высказывание и текст (диалогический и монологический). А ЛЕ изначально должны быть включены в коммуникацию. Однако мы не думаем, что предлагаемую методику мы должны строить «с нуля». Мы думаем, что традиционная методика по формированию лексических умений (умений, обеспечивающих коммуникацию) может сыграть нам добрую службу при осуществлении нашей концепции. Рассмотрим ниже эту (традиционную) методику, однако с точки зрения наших изначальных задач, а именно, задач по формированию лексических умений в профессионально ориентированном обучении китайских учащихся НЭ.

В традиционной методике по обучению лексике считается, что сформированное лексическое умение долж- но быть включено в речевую деятельность, связанную с пониманием мыслей других людей и выражением собственных мыслей. [Одинцова, 2004. С. 29-39]. Для формирования лексического умения используются коммуникативные упражнений [Пассов,1985. С. 109], или, иными словами, коммуникативные задания [Арутюнов, 1989]. Содержание коммуникативных заданий - это исполнение учащимися речевых действий в условиях, близких к условиям реальной коммуникации или таковых. Коммуникативные упражнения (задания) - это своего рода творческие упражнения. С позиции подхода коммуникативной активности такие упражнения считаются ведущими в работе иностранными (в том числе и китайскими) учащимися. Назовём основные требования к коммуникативным упражнениям (заданиям):

1. Наличие речевой ситуации, если возможно, воссоздание условий реальной коммуникации. Важность соблюдения этого условия была хорошо указана методистами В. Риверс, И.Паесовым и др. Работа в аудитории должна максимально точно имитировать условия реальной языковой коммуникации» [Пассов, 1985. С. 109].

2. Коммуникативные упражнения обеспечивают мотивацию говорящего.

3. Возникает структурное разнообразие высказывания, связанное с выходом за пределы воспринятого на занятии материала.

4. Коммуникативные упражнения должны обеспечивать максимальную и постоянную совместимость речевого материала с ситуацией общения, что приводит к повышению качества сформированных умений. 
5. Основное внимание уделяется первичному умению, связанному с когнитивно-речевыми механизмами: развитию определенного качества логических, семантических и синтагматических построений.

Коммуникативные упражнения, по мнению Л.С. Скалкина, включают в себя следующие типы: вопросоответный, ситуативный, репродуктивный (пересказ текста или видеосерии), проблемный и игровой[Скалкин, 1981]. Чтобы улучшить лексические навыки и развивать речевые умения (включение лексических навыков в речевую деятельность) при преподавании лексики на НЭ (начальном этапе) российских вузов (на ПФ), широко используются следующие типы:

1. Ситуативные упражнения. Ситуации могут быть созданы по-разному: проигрывания реальной ситуации в определённой сфере общения, описания, представления текста (диалогического)для прослушивания и разыгрывание его по ролям и т. д.

Учащимся предлагается составить собственное высказывание по предлагаемой теме. В этом случае могут быть указаны слова, вопросы и план ответа. Тема высказывания может быть предложена на основе прочитанного текста или быть свободной.

В качестве визуальной поддержки можно использовать тематические рисунки, серию изображений, фильм, видео. Например, 1: Вы знаете, что демонстрируется новый русский фильм, и вы хотите пригласить свою подругу в кинотеатр в субботу. Что вы ей скажете?

Ещё пример: 9.30, все пришли в институт на экзамен. Но Ван ещё не пришла. Ее друзья в группе очень волнуются. Она опоздала. Вопрос: Какие вопросы могут задать её друзья?

2. Пересказ. Эффективный тип упражнений, который способствует развитию механизмов памяти и механизмов корректной речи. Эффективность упражнения достигается за счет соблюдения ряда условий: пересказ должен выполняться;

а) с помощью ваших собственных слов;

б) с помощью слов, взятых из текста, но с конкретной речевой задачей.

В качестве задач используются следующие:

1. сжатие - детализация;

2. перенос действия в новую ситуацию и т. д.

При выполнении задания проверяется способность учащихся программировать высказывание, например на основе прочитанного текста (либо прослушанного и т. д.). Задача может быть направлена так же и на формирование диалогической речи (с указанием слов из списка). Например:Расскажите подробно (кратко) текст по заданным вопросам используя прямую речь (косвенную речь, от первого или третьего лица).

3. Использование мультфильмов и фильмов - очень эффективный способ развития речевых навыков. Например:
- Разыграйте диалог (диалоги) по содержанию фильма.

- Оцените действия героев.

- Оцените содержание фильма.

4. Пересказ с нахождением новой информации. Учащимся предлагается прослушать знакомый текст, который включает новую информацию. В соответствии с заданием учащиеся находят изменения и оценивают их с определённой точки зрения. При решении задачи можно использовать чертежи, серии чертежей, рисунки, схемы и т.д.

5. Рассказ или эссе по определенной теме. Это наиболее творческая задача, в результате которой формируется способность создавать высказывания на основе приобретенного речевого опыта. Тема сочинения может быть предложена на основе прочитанного, или самостоятельно выбранного текста. Например: Подготовьте сообщение (рассказ) на тему «Моя родная деревня»; «Наша будущая профессия».

6. Драматизация текста. Упражнения представляют большой интерес у студентов. Важно только выбрать темы для драматизации, которые соответствуют возрасту и интересам студентов.

7. Перевод текста на родной язык или на русский. Например: прочитайте текст о Ю.А. Ганарине. и кратко переведите его содержание с русского на китайский.

Описанные выше упражнения (задания) представляют, как мы уже отмечали выше, традиционную систему работы с лексикой в иностранной аудитории. С их помощью, как мы также отмечали выше, ЛЕ изначально могут быть включены в учебное общение преподавателя и учащихся, в нашем случае - в учебный процесс китайских учащихся ПФ в условиях российских вузов. Однако их использование в условиях учебно-профессионального общения на НЭ обучения требует некоторой корректировки. Оптимальное профессионально ориентированное обучение требует корректировки, прежде всего, по уровням владения учащимися языком, а также с точки зрения возможностей интегрирования ЛЕ (лексических единиц) из обиходно-бытовой сферы общения (и/или из социально-культурной) - в учебно-профессиональную. Для этого по периодам (сопряжённым с уровнем владения языком) нам необходимо выделить приоритеты.

Так, мы считаем, что при профессионально ориентированном обучении при формировании уровней $\mathbf{A} 1$ и А2 в учебный процесс будущих филологов необходимо включить следующие ЛЕ, позволяющие им лучше овладеть:

1. корректной речью вообще (здесь обеспечивается требование культуры речи будущих филологов);

2. корректной, профессионально ориентированной, речью учащегося - будущего филолога (что входит в профессиограмму филолога-русиста). 
При формировании у китайских учащихся коммуникативной компетенции уровня А1 в китайской аудитории прежде всего нужно учитывать тот факт, что китайским, правополушарным, учащимся весьма трудно перейти от китайского иероглифа - на русское звукобуквенное письмо. Поэтому с самого начала звуко-буквенные соответствия должны формироваться в составе целостных единиц: слов, словоформ, словосочетаний, предложений-высказываний, микротекстов. Поскольку многие китайские иероглифы представляют для учащегося нечто вреде микротекстов, то к русскому слову они относятся также как к микротексту. Поэтому с самого начала нужно вводить слова (словоформы) как целостные

Единицы на «карточках мгновенного предъявления», в рамках этих слов учащиеся лучше устанавливают звуко-буквенные соответствия, дифференцируют значения за счёт смыслоразличительных звуков (или, в дальнейшем, букв). Китайским учащимся НЭ обучения со свойственной им стратегией «от синтеза - к анализу» не следует в самом начале давать задание «Построить предложение из слов...» (такое задание можно давать позже для формирования их компенсаторных стратегий). Лучше в первый месяц их учёбы включать новые слова в предложение-высказывание, или в микротекст (диалогический/монологический). Поначалу оптимальная методика для нашего контингента - включать новые ЛЕ в диалогические единства, предъявлять эти единства в устной форме (по ходу продублировав их в письменной для идентификации и усвоения букв в их функционале), а затем разыгрывать:

а) диалогические единства;

б) микротексты-диалоги.

Доминирующими сферами учебного общения в данный период должны быть: а) учебно-профессиональная сфера (овладение (элементарное) которой обеспечивает реальное общение в аудитории);

в) обиходно-бытовая сфера (овладение (элементарное) которой обеспечивает реальное общение за пределами академической среды). Поэтому главной концепцией введения русской лексики в тезаурус ЯЛ китайского учащегося должна быть концепция, направленная на введение ЛЕ, покрывающих отобранную коммуникативно значимую, текстотеку.

Профессионально значимую лексику следует вводить в зависимости от задач конкретного учебного общения. Так, при реализации вводно-фонетического курса (первые две недели обучения на ПФ) в соответствии с «Программой...» [Программа, 2017] вводятся ЛЕ буква и звук. Мы считаем, что помимо этих единиц следует вводить ЛЕ (термины) «гласный» и «согласный», «мягкий» и «твёрдый», «ударный» и «безударный», «краткий» (с демонстрацией соответствующих звуков). Это позволит не только с самого начала формировать корректное произношение, но и лучше понимать профессионально-ориентированные тексты в будущем: во втором семестре ПФ при введении специальных предметов, как, например, языкознание. В этом случае учащимся гораздо легче будет понимать следующий микротекст: «Звуки русского языка делятся на гласные [a, o, у, э, и, ы] и согласные [б,

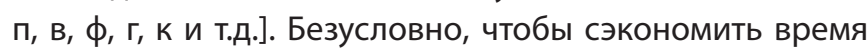
и обеспечить хорошее качество усвоения в этот период необходимо интегрировать некоторые общеупотребительные ЛЕ в профессионально ориентированные высказывания/микротексты. Например, ЛЕ «мягкий»и «твёрдый» нужно сразу давать в нескольких их значениях и функциях, эксплицировав данные значения и функции в словосочетаниях, а также продемонстрировав наглядными пособиями: 1) мягкий знак ( ь ); 2) мягкий диван; мягкий звук [ ч *]. Такая же работа должна быть проведена с ЛЕ «твёрдый».

При формировании у китайских учащихся коммуникативной компетенции уровня $\mathbf{A 2}$ в китайской аудитории прежде всего нужно учитывать тот факт, что китайские , правополушарные, учащиеся уже в некоторой степени адаптировались в российской культурноязыковой действительности. Они усвоили (в некоторой степени) русское звуко-буквенное письмо, а также, в некоторой степени, овладели техникой чтения. И сейчас им комфортнее работать так, как они привыкли в китайской школе: работать с письменными источниками информации, с микротекстами и текстами. Понимание микротекстов/текстов в этот период обеспечивается не только усвоением «предыдущей» лексики, но и усвоением грамматики: по крайней мере, они знают именные (все падежи существительных в их первичной функции) и глагольные формы. Поэтому новые ЛЕ следует включать в варианты знакомых по структуре микротекстов. В этом случае значение нового слова легче понимается и усваивается за счёт контекста и языкового окружения (на основе ассоциативных связей).

Главной задачей данного периода обучения является задача оптимального включения в учебное общение ЛЕ, актуальных в их настоящем и будущем учебно-профессиональном общении. В этом плане весьма важной задачей является введение (или «подкрепление») так называемых структурообразующих слов. Например, выше мы приводили высказывание «Звуки русского языка делятся на гласные и согласные». Здесь структурообразующей ЛЕ является ЛСВ «делятся на». В данный период весьма важно давать учащимся ЛЕ с привлечением морфологического анализа, что в будущем также обеспечит понимание текстов с привлечением «языковой догадки». 
Выше мы изложили нашу концепцию формирования у китайских учащихся, будущих филологов, промежуточной коммуникативной компетенции с дифференциацией уровней A1 и A2. Также попытаемся высказать наши соображения по использованию наработок традиционной методики в зависимости от периода обучения.

1. При формировании у китайских учащихся коммуникативной компетенции уровня А1 ЛЕ единицы могут быть включены в коммуникацию за счёт:

1) создания ситуаций (ситуативных упражнений);

2) представления текста (диалогического)для прослушивания и разыгрывание его по ролям;

3) представления текста (диалогического) в его письменной форме, прочтение и разыгрывание его по ролям;

4) прочтения учебного микротекста/текста и организации тематической беседы по тексту;

5) пересказа микротекста без его изменения (репродукция):

а) в опоре на картинки, рисунки, чертежи, схемы, таблицы, ключевые слова, вопросный план;

б) без опор;

6) создания аналогичного микротекста на основе прочитанного/услышанного (продукция);

7) перевода с РЯ на китайский.

2. При формировании у китайских учащихся коммуникативной компетенции уровня $\mathrm{A2}$ ЛЕ единицы могут быть включены в коммуникацию за счёт:

1) тех же методических средств, которые мы выделили применительно к первому периоду (при формировании уровня А1), а также:

2) за счёт чтения текста и его пересказа с дополнительной задачей:

а) по плану;

б) по ключевым словам;

в) на сжатие/детализацию текста;

г) на продолжение изложенного текста;

3) за счёт просмотра мультфильма/фильма и его пересказа:

а) от лица участника действия;

б) от лица стороннего наблюдателя;

в) с его оценкой и т.д.;

4) за счёт «драматизации» текста;

5) за счёт включения ЛЕ в проектную деятельность.

Практика преподавания русского языка китайским учащимся-филологам в России (довузное обучение) показывает, что все эти способы непосредственного включения ЛЕ в коммуникативную деятельность весьма эффективно.

\section{Зак^ючение}

Таким образом, семантизация новых слов с помощью видимости, перевода и интерпретации на их родном языке является наиболее характерной, наиболее оптимальной и доступной на начальном этапе для кругов всех типов. И методы семантизации, основанные на анализе словообразования, и контекст, который развивает умение языковой гипотезы, особенно важны для тех, кто изучает русский язык, чтобы читать специальную литературу и газеты [Гапочка, 2000].

Примеры, облегчающие запоминание лексики. Мы знаем, что самое твердое слово запоминается, если оно вводится в момент острой необходимости в нем. Создавая ситуацию необходимости слова, хотя он имеет смысл и как можно более эмоционально окрашен, учитель получает возможность мгновенно ввести его в память учеников. Это может быть вопрос, ответ на который требует слова, запланированного для введения, и только это; это может быть формулировка оценки или доказательства, т.е. такое заявление, когда важно, чтобы оратор оценивал не только учителя, но и других учащихся, когда можно не только сделать языковые ошибки, но и сделать неточность. Понятно, что особая потребность в слове возникает естественным образом.

Очень хороший результат - введение новых слов в эмоционально окрашенную ситуацию. Использование произведений искусства, интерес к тому, что происходит в классе, своеобразная, расслабленная атмосфера как бы «раскрывает» восприятие.

Другим, не менее мощным фактором, помогающим запоминать, является наличие когнитивного интереса к исходному материалу. Всем известно, что чем выше мотивация, тем лучше результат обучения, и наоборот. Основным направлением в развитии такого интереса является устранение концепции «безличности» слова.

Отдельным и важным аспектом работы является сообщение региональной информации, содержащейся в этом слове. Например, вводя лексическую единицу «детский сад», необходимо не только сообщить свое значение, но и кратко перечислить информацию об этом учреждении, известную каждому русскому человеку.

Известно, что независимо от того, насколько важным является этап представления слова, он, однако, является лишь первым шагом в процессе обучения лексике. Основной этап этого методического процесса - этап организации ассимиляции новой лексики. 


\section{ЛИТЕРАТУРА}

1. Колкер Я.М., Устинова Е.С. Как достигается сотрудничество преподавателя и обучаемого// Иностранные языки в школе. 2000. № 1. - с.28-32.

2. Константинова 0.В. Компьютерная программа и ее место в обучении языку специальности иностранных студентов технических вузов//Мир русского слова. 2000. №3. - с.54-58.

3. Корчагина Е.Л. 0 стратегии составления современных программ по русскому языку как иностранному//Русский язык за рубежом. 2000 №1. - с.79-85.

4. Костомаров В.Г., Митрофанова 0.Д. Методические руководства для преподавателей русского языка иностранцам. 4-е изд., перераб. и доп. М., 1988. 157 c.

5. Леонтьев А.А. Слово в речевой деятельности. М. 2003. - 245 с.; Москалева 0.Н. Разработка и использование компьютерных игр в самостоятельной работе по русскому языку как иностранному. Дисс... канд. пед. наук, М., 2004. - 207 с.

6. Мульруд Р.П. Актуальные проблемы методики обучения иностранным языкам за рубежом// Иностранные языки в школе. 2004 №3. - с.34-40.

7. Олейникова 0.Н., Новикова Т.Ю. Из опыта создания видеокурса для начально-среднего этапа обучения РКИ//Мир русского слова. 2000 №4. - с.77-79.

8. Пассов Е.И. Основы коммуникативной методики обучения иноязычному общению. М., 1985. - 276 с.

9. Пассов Е.И. Развитие индивидуальности как цель иноязычного образования// Мир русского слова. 2001.№..-с. 18-36.

10. Полат Е.С. Метод проектов на уроках иностранного языка// Иностранные языки в школе. 2000. № 2,3. - с.3-9.

11. Полат Е.С. Обучение в сотрудничестве// Иностранные языки в школе. 2000. № 1. - с.4-10.

12. Половникова В.И. Лексический аспект в преподавании русского языка на продвинутом этапе. М., 1982. - 204 с.

13. Практическая методика обучения русскому языку как иностранному. Под ред. А.И. Щукина. М., 2003. - 304 с.

14. Скалкин В.Л. Основа обучения учебной иностранной речи. М., 1981. - 180; Тер-Минасова С.Г. Язык и межкультурная коммуникация. М., $2000 .-263$ с.

15. Щукин А.П. Методика использования аудиовизуальных средств (при обучении русскому языку как иностранному в вузе). М., 1981. - 218 с.

16. Щукин А.Н. Методика преподавания русского языка как иностранного: Учебное пособие для вузов. М.: Высшая школа, 2003. - 334 с.

○ Чэнь Сюе (437118032@qq.com).

Журнал «Современная наука: актуальные проблемы теории и практики»

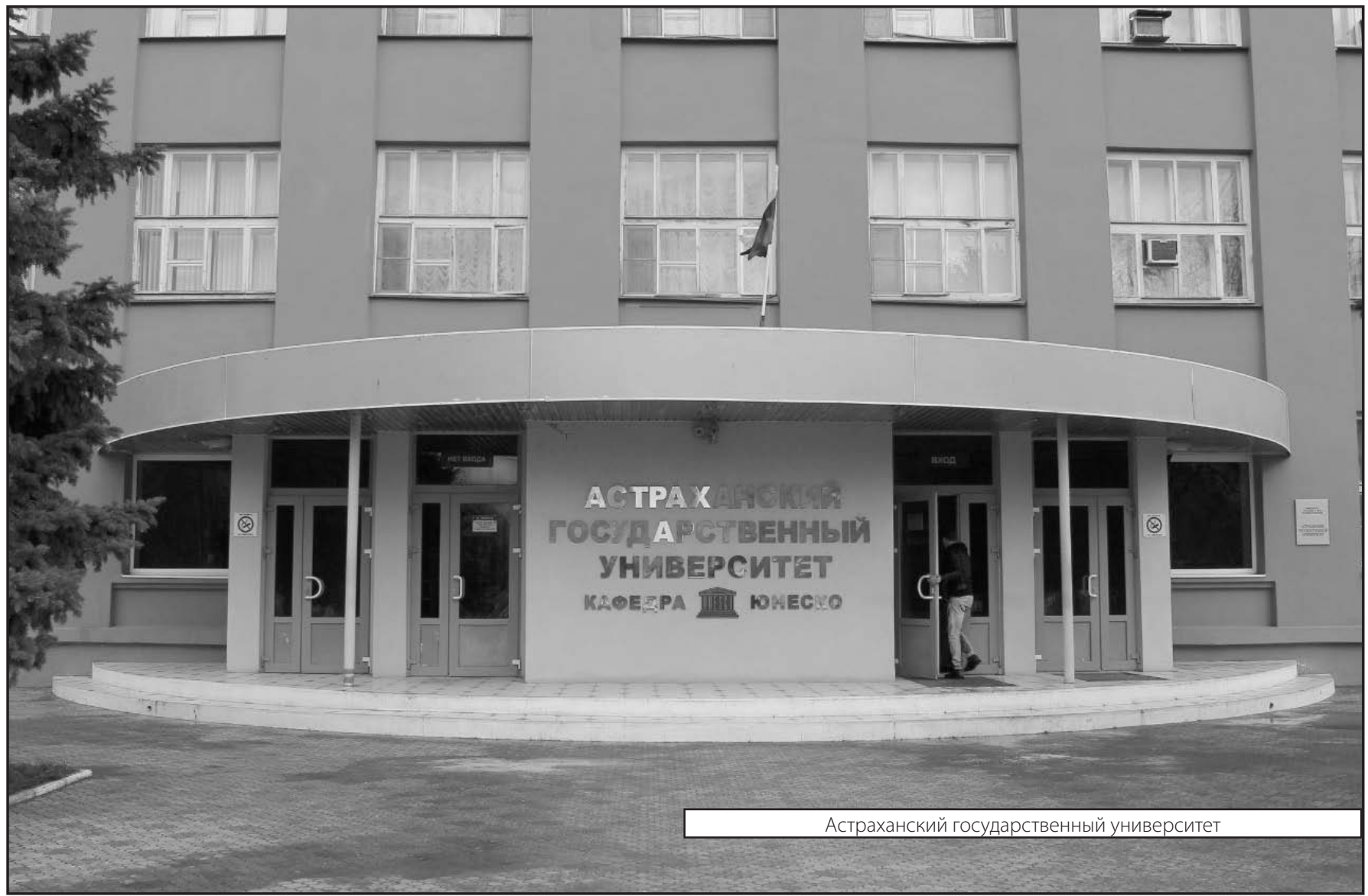

